\title{
The Impact of Proteomic Investigations on the Development and Improvement of Skin Laser Therapy: A Review Article
}

\author{
Shabnam Shahrokh ${ }^{1}$, Zahra Razzaghi ${ }^{2}$, Vahid Mansouri ${ }^{*}$, Nayebali Ahmadi ${ }^{3}$ \\ ${ }^{1}$ Gastroenterology and Liver Diseases Research Center, Research Institute for Gastroenterology and Liver Diseases, Shahid \\ Beheshti University of Medical Sciences, Tehran, Iran \\ ${ }^{2}$ Laser Application in Medical Sciences Research Center, Shahid Beheshti University of Medical Sciences, Tehran, Iran \\ ${ }^{3}$ Proteomics Research Center, Faculty of Paramedical Sciences, Shahid Beheshti University of Medical Sciences, Tehran, \\ Iran
}

\section{*Correspondence to Vahid Mansouri, Proteomics Research Center (PRC), Darband St., Qods Sq., Tehran, Iran. Tel: +982122714248; \\ Email:vm1343@yahoo.com}

Published online December 1 , 2019

\begin{abstract}
Introduction: Different molecular approaches have contributed to finding various responses of skin to external and internal tensions such as laser irradiation and many important mediators of skin disease have been identified through these approaches. However, different essential signals of skin biomarker pathways and proteins are partially detected or completely unknown. In the present study, the impact of proteomics on the evaluation of laser therapy for the treatment of skin diseases is investigated.

Methods: The keywords of "Proteomics", "Laser therapy", "Skin", and "Skin disease" were searched in Google Scholar, Scopus and PubMed search engines. After screening, 53 documents were included in the study.

Results: The global assessments revealed that different proteins in different signaling pathways of skin metabolism in terms of health or illness after laser therapy are expressed differentially. The results indicated that the application of proteomics is a useful method for promoting the results of laser interventions.

Conclusion: This kind of research dealt with the practical proteomics of skin diseases and skin laser therapy.

Keywords: Protein, Skin diseases, Proteomics, Laser therapy
\end{abstract}

\section{Introduction}

The use of a low-power laser (LPL) to reduce infection, pain and edema, wound healing, plus superficial nerve repair has been known for many years. ${ }^{1-3}$ The LPL usage in dermatology has attracted the attention of many researchers recently. ${ }^{4,5}$

This article reviews the molecular mechanisms that LPLs perform on the skin and various skin diseases. In this regard, the database of comprehensive proteomic studies concerning altered proteins in the skin laser therapy has been reviewed. This paper presents what advances have been made in the application of proteomics in introducing molecular interactions between proteins in different cellular and molecular cycles after laser application in the treatment of skin diseases. However, there is a large capacity for performing a wide range of investigations in the field of proteomics and laser therapy. In Figure 1, the schematic relationship between proteomic investigations and laser therapy improvement is presented.

\section{Methods}

The search engines of Google Scholar, Scopus, and PubMed were used to search such keywords as "Proteomics", Laser therapy", "Skin", and "Skin disease". The identified titles in English were studied and the relevant ones were selected for more assessment. The abstracts of 150 documents were investigated that led to select 97 full texts. Among 97 articles, 53 documents were suitable to include in the study.

\section{Laser Devices and Properties}

A laser is a device that typically generates electromagnetic radiation. The ruby laser, as described in 1960, is uniform in the wavelength, phase, and polarization. ${ }^{6}$ The laser beam has both light and radiation energy. ${ }^{7}$ Biological systems could be affected by the LPL as a non-thermal kind. ${ }^{8}$ Mester et al started to investigate about the LPL in 1967 as the non-thermal effects of lasers on the growth of mouse hair. ${ }^{9}$ As Posten et al reported, low-level lasers

Please cite this article as follows: Shahrokh S, Razzaghi Z, Mansouri V, Ahmadi N. The impact of proteomic investigations on the development and improvement of skin laser therapy: a review article. J Lasers Med Sci. 2019;10(suppl 1):S90-S95. doi:10.15171/jlms.2019. S16. 


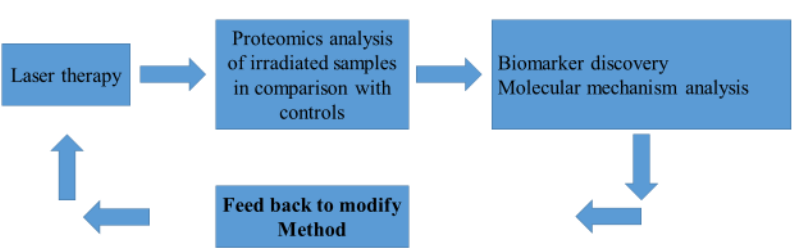

Figure 1. The Schematic Relationship Between Proteomics Studies and Laser Therapy Improvement.

(LLLs) have these properties: the power output of lasers is ranged between 0.001 and 0.1 ; the wavelength is in the range of 300-10600 nm; pulse rate from 0 to $5000 \mathrm{~Hz}$ (cycles per second).; and the intensity is $0.01-10 \mathrm{~W} / \mathrm{cm}^{2}$ with a dose of 0.01 to $100 \mathrm{~J} / \mathrm{cm}^{2} .{ }^{10}$ Popular methods in the administration of LLL radiation include ruby $(694 \mathrm{~nm})$, Ar (514 and $488 \mathrm{~nm})$, He-Ne (632.8 nm), Ga-Al-As (650 or $805 \mathrm{~nm}$ ), and Krypton (521, 530, 568, and $647 \mathrm{~nm}){ }^{11}$ Basically, the use of light for improving healing, reducing infection and relieving pain in biological systems can be considered as the application of a LPL. Unlike other medical laser techniques, LPLs do not have ablative or thermal effects, but the photochemical effects have been reported. The photochemical effect refers to the absorption of light by skin and chemical changes. ${ }^{12}$ Other kinds of laser therapy for ablation and cutting tissues and thermal tissue coagulation are not comparable to an LPL. $^{13}$

\section{Laser Impact on Cell Biology}

The reason for LLL therapy usage is the low-density delivery of energy. ${ }^{14}$ Several kinds of studied samples in this article are tabulated in Table 1. Some molecular photo-acceptors named chromophores in target tissues could absorb photons by their electronic absorption bands treated by LLL therapy. ${ }^{14}$ Recent researches have shown that LLL affects mitochondria and cytochrome C. ${ }^{12}$

Cytochrome c oxidase (Cox) is the primary photo acceptor for the red-NIR range in mammalian cells. ${ }^{15}$ Excited electrons in Cox lead to more electron transportation, leading to more ATP production. ${ }^{16}$ On the other hand, Cox activity is inhibited by nitric oxide. ${ }^{17}$ Investigations indicate that inhibition caused by $\mathrm{NO}$ binding to Cox could be reversed by the LPL or LPL in separated mitochondria or inside cells. ${ }^{18}$ The LPL shifts the cell reactions to greater oxidations ${ }^{19}$ and increases ROS generation. ${ }^{20}$ The effect of LPL on gene expression alteration, cell proliferation and remodeling, synthesis and DNA repair, and ion channels and membrane potential has been reported. ${ }^{21}$ The LPL has beneficial effects on wrinkles, acne scars, hypertrophic scars, and the healing of burns in dermatology. ${ }^{4}$ The effects of laser therapy on neuropathic pain were analyzed in rats. ${ }^{22}$ Orringer et al quantified the molecular changes resulted from micro ablative resurfacing by the erbium: yttrium aluminium garnet (Er:YAG) laser. They found the up-regulation of keratin 16 , IL-1B, and IL-8. In this research, the up-
Table 1. Several Types of Studied Samples in This Article

\begin{tabular}{lc}
\hline Studied Sample or Affected Target & Ref. \\
\hline Mitochondria and cytochrome C & 12 \\
Cytochrome c oxidase & 15 \\
Wrinkles, acne scars, hypertrophic scars, and healing of burns & 4 \\
Neuropathic pain & 22 \\
Extracellular matrix & 23 \\
Skin incisions & 24 \\
Photo-damaged face and neck skin & 25 \\
Different layers of the skin & 26,27 \\
Foot and breast skin & 28 \\
Keratinocytes & 30 \\
Human epidermis stem cells and transit amplifying cells & 32 \\
\hline Cytokeratin & $40-42$ \\
\hline Rho GDP-dissociation inhibitor1 & 43 \\
\hline Human arm skin & 52 \\
\hline Human gingival fibroblasts & 53 \\
\hline
\end{tabular}

regulation of MMP-1 and MMP-3 of the extracellular matrix (ECM) was also remarkable. They concluded that after laser peeling by Er-YAG; collagen build-up process is increased and a wrinkles are decreased. ${ }^{23}$ On the other hand, the application of the PIRL laser to skin incisions indicates that the following events happen: minimal ablation of tissue, less damage to surrounding tissue resulting in the reduced activation of $\beta$-catenin and TGF-b signaling, more cell viability, decrease of cell proliferation, collagen deposition sooner in the scar, and thus an accelerated healing response. ${ }^{24}$ The $\mathrm{CO}_{2}$ laser resurfacing photo-damaged face and neck skin demonstrated the upregulation of MMPs 1, 3, 9, and 13 as well as MMP-10 and MMP-11.25

\section{Proteomics and Skin}

Proteomics is a large-scale study of proteins and proteome is the entire set of proteins produced or modified by a system or a cell. Proteomics could cover the exploration of proteomes from the overall level of protein composition, structure, and activity in skin. Conventional methods have shown the presence of collagen type I, III, VII, IV and reticular and elastin fibers along with laminin, nidogen, entactin, and heparin sulfate proteoglycans in different layers of the skin. ${ }^{26,27}$ Since proteomic techniques do not have limitations like dyeing techniques and immuno-histochemistry, they can be used to introduce various proteins in the skin. For example, in a study that investigated foot skin proteins compared to the breast skin, fifty common and more prominent proteins in the skin of both regions were found as collagen, creatine and ECM proteins such as lumacan, cDNA highly similar to mimecan, periostin, biglycan, decorin, prolargin, and elastin. However, in the breast skin, only tenascin-x and other uncharacterized protein were found and in 
the leg skin, only serum amyloid P-component vice versa was found. ${ }^{28}$ Another study that investigated the functional aspects of the skin proteomics revealed the comprehensive proteomic profiling of the rats' skin. ${ }^{29}$ Thousands of protein spots were digested by enzymes to identify thousands of proteins. Matching algorithms for isolated peptides accompanied by bioinformatics analysis performed as other global assessments have been done.

To understand the skin and keratinocytes responses to injuries, the oligonucleotide microarray technique is suitable. ${ }^{30}$ The microarray has enabled the analysis of large numbers of genes. However, this technique could not supply data about the transitional regulation of protein expression. One of the disadvantages of this technique is the lack of access to the conformational and steady state information of proteins along with the post-transitional alterations or modifications of proteins in steady levels such as glycosylation and phosphorylation. Therefore, proteomics could manage to profile most proteins and their isoforms which are expressed in glycosylation and phosphorylation as post-transitional modification and proteolytic cleavages. Interferon-g-induced polypeptides are up-regulated in old patients, revealed by proteomic profiling of epidermis in the skin; therefore, the $\mathrm{p} 85 \mathrm{~b}$ subunit of phosphatidylinositol 3-kinase and manganesesuperoxide dismutase could be induced. ${ }^{31}$ Proteomics techniques can compare the stem cells of human epidermis with transit amplifying cells (their differentiated daughter cells). Based on this finding, epidermal fatty acid binding proteins (PA-FABP) along with annexin II, and other keratin related proteins were deregulated in the transit amplifying cells. ${ }^{32}$ They suggest that PA-FABP is a novel marker for transit amplifying cells. Seven new human epidermal protein markers were identified for skin irritation via proteomics. HSP27 was identified as the most prominently up-regulated protein among these 7 proteins. They suggested HSP27 as a skin irritation sensitive marker. ${ }^{33}$ To understand the global protein pattern of skin, an effort for identifying the expression of proteins in the murine skin has been initiated. Huang et al constructed a map for reference proteins of BALB/c murine abdominal skin via proteomics. They used PDQuest software (BioRad, Hercules, CA) to detect more than 500 protein spots. 44 of those spots corresponded to 28 different proteins. They could be distinguished by using laser mass spectrometry (MALDI-TOF MS) and a suitable algorithm of probability-based database-searching subsequently. ${ }^{34}$

Proteomic analysis of laser microdissected melanoma cells of skin revealed that proteins such as tenascin-C, fibronectin and $\alpha$-actinin- 4 are up-regulated in melanoma cells to increase invading characters of melanoma cells in the culture. ${ }^{11}$

Rezaei-Tavirani et al represented critical proteins as GAPDH, RHOA, DCTN2, PDIA3, AKT1, PRNP, RPSA, TPT1, HSPB1, and TP53. They play important roles when skin is exposed to laser irradiation. They believed that there is a balance between cancer promotion and skin treatment with Laser irradiation. ${ }^{35}$

\section{Skin and Laser Therapy}

Skin aging has some problems such as tissue elasticity reduction, wrinkling, telangiectasia, and dyspigmentation. Other features like the reduction of collagen and the fragmentation of collagen fibers in company with the degeneration of elastic fibers, tortuous dermal vessel appearance, and the up-regulation of matrix metalloproteinases $1 \& 2$ (MMPs) are significant with epidermal atrophy in aged skin. ${ }^{36}$ Such factors as time and environment could influence skin normal aging; however, UV skin photo damaging is the most effective factor responsible for skin aging. ${ }^{37}$

Laser resurfacing is a treatment for reducing facial wrinkles and skin deformities such as blemishes or acne scars. The technique shoots concentrated pulsating beams of light at irregular skin to remove skin layer by layer. Laser therapy has some risks, including bleeding, infection, pain, scarring, and changes in skin color, but people also tend to be healed faster with laser operations. In a research study, using the erbium-YAG laser to assess the damages and changes to mouse skin revealed a significant increase in trans-epidermal water loss and erythema with the skin $\mathrm{pH}$ at 4 after 24-hour laser therapy. These effects decreased to a baseline after 96 hours. Following exposure to the laser, p21 and p53 proteins were up-regulated significantly in the cells of skin. This up-regulation means p53 protein supports DNA repair to survive skin..$^{38}$ Another crucial role of laser irradiation is reported during the responses to stress as arrest of $\mathrm{G}_{1}$ phase of cell cycle. ${ }^{39}$ However, by low flounce-laser therapy $\left(7.5 \mathrm{~J} / \mathrm{cm}^{2}\right)$, the nuclear antigen belongs to proliferation down-regulated as the cytokeratin expressions. The see-saw apoptosis and proliferative mechanisms occur by skin laser irritation. Coagulation, necrosis and scars correspond to the Er:YAG laser. ${ }^{40}$ The expression of cytokeratin remarkably decreases following laser treatment. ${ }^{41}$ Cytokeratin down-regulation leads to changes in blistering and vacuolization. ${ }^{42}$ Researchers reported that one of the members of molecular chaperones (Rho GDP-dissociation inhibitor1 or Rho GDI 1) in metastatic carcinoma was overexpressed. ${ }^{43}$ However, Rho GDI 1 expression was down-regulated after laser therapy in proteomics assays. Rho GDI 1 down-regulation is equal to the modulation of Rho protein activities. This led to the disruption of the actin cytoskeleton which was associated with new keratinocytes moving to replace those keratinocytes killed by the laser. ${ }^{40}$ The concentration of Heat shock protein or HSP25 changed according to the place of keratinocytes. HSP 25 increased in the upper keratinocytes from the basal layer as the extent of keratinization was also higher in surface keratinocytes. ${ }^{44}$ Laser therapy could damage the skin cells according to HSP26 reduction 24 hours after treatments. ${ }^{40}$ Laser irradiation can cause epidermal cell death and loss 
of vital cells. ${ }^{45}$ It may be consistent with post-apoptotic necrosis. ${ }^{46}$ PCNA is a marker to provide further insights into laser-tissue interactions. Polymerase D is a marker for cell proliferation and PCNA is reported as an auxiliary protein or cyclin for polymerase D. ${ }^{46} \mathrm{P} 21$ DNA damageinduced cell cycle arrested by inhibiting PCNA leads to the up-regulation of $\mathrm{P} 21{ }^{47}$

Recently network analysis has been applied to the evaluation of proteomic findings from the studies into diseases. In this method, a large number of proteins interact to construct an interactome. Network analysis

Table 2. Five Classes of Biological Terms Related to the Deregulated Genes in the Arm Skin After $\mathrm{CO}_{2}$ Laser Therapy

\begin{tabular}{|c|c|c|}
\hline Cluster & $\mathbf{R}$ & Biological Term \\
\hline 1 & 1 & Cytokine-mediated signaling pathway \\
\hline \multirow{4}{*}{2} & 1 & Interferon gamma signaling \\
\hline & 2 & Response to interferon-gamma \\
\hline & 3 & Cellular response to interferon-gamma \\
\hline & 4 & Interferon-gamma-mediated signaling pathway \\
\hline \multirow{5}{*}{3} & 1 & Hepatitis C \\
\hline & 2 & Measles \\
\hline & 3 & Influenza A \\
\hline & 4 & Herpes simplex virus 1 infection \\
\hline & 5 & Epstein-Barr virus infection \\
\hline \multirow{12}{*}{4} & 1 & Hepatitis C \\
\hline & 2 & Measles \\
\hline & 3 & Influenza A \\
\hline & 4 & Herpes simplex virus 1 infection \\
\hline & 5 & Antiviral mechanism by IFN-stimulated genes \\
\hline & 6 & Interferon alpha/beta signaling \\
\hline & 7 & Interferon Signaling \\
\hline & 8 & Response to type I interferon \\
\hline & 9 & Negative regulation of the viral process \\
\hline & 10 & Regulation of the viral process \\
\hline & 11 & Cellular response to type I interferon \\
\hline & 12 & Type I interferon signaling pathway \\
\hline \multirow{21}{*}{5} & 1 & Hepatitis C \\
\hline & 2 & Antiviral mechanism by IFN-stimulated genes \\
\hline & 3 & Cytokine Signaling in the Immune system \\
\hline & 4 & Interferon alpha/beta signaling \\
\hline & 5 & Interferon Signaling \\
\hline & 6 & Regulation of the multi-organism process \\
\hline & 7 & Negative regulation of the multi-organism process \\
\hline & 8 & $\begin{array}{l}\text { Regulation of symbiosis, encompassing mutualism } \\
\text { through parasitism }\end{array}$ \\
\hline & 9 & Response to virus \\
\hline & 10 & Defense response to other organisms \\
\hline & 11 & Response to type I interferon \\
\hline & 12 & Negative regulation of the viral process \\
\hline & 13 & Regulation of the viral process \\
\hline & 14 & Defense response to the virus \\
\hline & 15 & Viral life cycle \\
\hline & 16 & Viral genome replication \\
\hline & 17 & Cellular response to type I interferon \\
\hline & 18 & Regulation of the viral life cycle \\
\hline & 19 & Negative regulation of the viral life cycle \\
\hline & 20 & Type I interferon signaling pathway \\
\hline & 21 & Negative regulation of viral genome replication \\
\hline
\end{tabular}

leads to introducing the critical ones that play crucial roles in the diseases. ${ }^{48-50}$ Using protein-protein interaction network analysis, researchers analyzed proteomics and large-scale data after laser irradiation in skin and diabetic retinopathy. ${ }^{51,52}$ They reported that 43 biological terms (see Table 2) clustered in five groups were related to the critical genes which were dysregulated in the arm skin after $\mathrm{CO}_{2}$ laser therapy.

Ogita et al reported that the protein expression of human gingival fibroblasts which were exposed to lowlevel Er:YAG laser irradiation one day after exposure changed. Based on their documents, 59 proteins were upregulated and 15 ones were down-regulated. Galectin-7 that is known as an important factor in wound healing was included in the up-regulated proteins. This experiment revealed that laser irradiation was associated with cell proliferation increment in human gingival fibroblast. ${ }^{53}$

\section{Conclusion}

As it was mentioned above, many proteins are associated with laser therapy, especially in skin treatment. However, several of them have been detected and recognized and there are large numbers of proteins that have not been determined. Proteomics is a useful method which in cooperation with the other large-scale methods and bioinformatics is able to analyze the large and varied data available on various skin investigations. It seems that many proteins, whose roles have not yet been determined, can be identified by proteomic investigations in the near future.

\section{Ethical Considerations}

Not applicable.

\section{Conflict of Interests}

The authors declare no conflict of interest.

\section{Acknowledgment}

Laser Application in Medical Sciences Research Center of Shahid Beheshti University of Medical Sciences supported this research.

\section{References}

1. Enwemeka CS, Parker JC, Dowdy DS, Harkness EE, Harkness LE, Woodruff LD. The efficacy of low-power lasers in tissue repair and pain control: a meta-analysis study. Photomed Laser Surg. 2004;22(4):323-9. doi: 10.1089/pho.2004.22.323.

2. Stergioulas A. Low-level laser treatment can reduce edema in second degree ankle sprains. J Clinic Laser Med Surg. 2004;22(2):125-8. doi: 10.1089/104454704774076181.

3. de Souza SC, Junqueira JC, Balducci I, Koga-Ito CY, Munin E, Jorge AOC. Photosensitization of different Candida species by low power laser light. J Photochem Photobiol B. 2006;83(1):34-8. doi: 10.1016/j.jphotobiol.2005.12.002.

4. Avci P, Gupta A, Sadasivam M, Vecchio D, Pam Z, Pam $\mathrm{N}$, et al . Low-level laser (light) therapy (LLLT) in skin: 
stimulating, healing, restoring. Semin Cutan Med Surg. 2013; 32(1): 41-52.

5. Wheeland RG. Clinical uses of lasers in dermatology. Lasers Surg Med. 1995;16(1):2-23. doi: 10.1002/lsm.1900160103.

6. Maiman TH. Stimulated optical radiation in ruby. Nature. 1960; 187: 493-494

7. Verma SK, Maheshwari S, Singh RK, Chaudhari PK. Laser in dentistry: An innovative tool in modern dental practice. Natl J Maxillofac Surg. 2012;3(2):124-32. doi: 10.4103/09755950.111342 .

8. Lin F, Josephs SF, Alexandrescu DT, Ramos F, Bogin V, Gammill V, et al. Lasers, stem cells, and COPD. J Transl Med. 2010;8(1):16. doi: 10.1186/1479-5876-8-16.

9. Mester E, Szende B, Tota J. Effect of laser on hair growth of mice. Kiserl Orvostud. 1967;19:628-31.

10. Posten W, Wrone DA, Dover JS, Arndt KA, Silapunt S, Alam M. Low-level laser therapy for wound healing: mechanism and efficacy. Dermatol Surg. 2005;31(3):33440. doi: 10.1111/j.1524-4725.2005.31086.

11. Hood BL, Grahovac J, Flint MS, Sun M, Charro N, Becker $\mathrm{D}$, et al. Proteomic analysis of laser microdissected melanoma cells from skin organ cultures. J Proteome Res. 2010;9(7):3656-63. doi: 10.1021/pr100164x.

12. Huang YY, Chen AC, Carroll JD, Hamblin MR. Biphasic dose response in low level light therapy. Dose Response. 2009;7(4): 358-383. doi: 10.2203/dose-response.09-027. Hamblin

13. Hamblin MR, Demidova TN. Mechanisms of low level light therapy. In: Mechanisms for low-light therapy. Vol. 6140. International Society for Optics and Photonics; 2006. doi: $10.1117 / 12.646294$

14. Sutherland JC. Biological Effects of Polychromatic Light. Photochem Photobiol. 2002;76(2):164-70. doi:10.1562/00318655(2002)076<0164:beopl>2.0.co;2.

15. Karu TI, Kolyakov SF. Exact action spectra for cellular responses relevant to phototherapy. Photomed Laser Surg. 2005;23(4):355-61. doi: 10.1089/pho.2005.23.355.

16. Passarella S. He-Ne laser irradiation of isolated mitochondria. J Photochem Photobiol B. 1989;3(4):642-3. doi: 10.1016/1011-1344(89)80090-9.

17. Beltrán B, Mathur A, Duchen MR, Erusalimsky JD, Moncada S. The effect of nitric oxide on cell respiration: a key to understanding its role in cell survival or death. Proc Natl Acad Sci. 2000;97(26):14602-7. doi: 10.1073/ pnas.97.26.14602.

18. Borutaite V, Budriunaite A, Brown GC. Reversal of nitric oxide-, peroxynitrite- and S-nitrosothiol-induced inhibition of mitochondrial respiration or complex I activity by light and thiols. Biochim Biophys Acta. 2000;1459(23):405-12. doi: 10.1016/s0005-2728(00)00178-x.

19. Karu T. Primary and secondary mechanisms of action of visible to near-IR radiation on cells. J Photochem Photobiol B. 1999;49(1):1-17. doi: 10.1016/S1011-1344(98)00219-X.

20. Alexandratou E, Yova D, Handris P, Kletsas D, Loukas S. Human fibroblast alterations induced by low power laser irradiation at the single cell level using confocal microscopy. Photochem Photobiol Sci. 2002;1(8):547-52. doi: 10.1039/b110213n.

21. Gilbertson DG, Duff ME, West JW, Kelly JD, Sheppard PO, Hofstrand PD, et al. Platelet-derived growth factor C (PDGF-C), a novel growth factor that binds to PDGF a and $\beta$ receptor. J Biol Chem. 2001;276(29):27406-14. doi: 10.1074/jbc.M101056200.

22. Micheli L, Cialdai F, Pacini A, Branca JJV, Morbidelli L, Ciccone V, et al. Effect of NIR laser therapy by MLS-MiS source against neuropathic pain in rats: in vivo and ex vivo analysis. Sci Rep. 2019;9(1):9297. doi: 10.1038/s41598-01945469-5.

23. Orringer JS, Rittié L, Hamilton T, Karimipour DJ, Voorhees JJ, Fisher GJ. Intraepidermal erbium:YAG laser resurfacing: impact on the dermal matrix. I Am Acad Dermatol. 2011;64(1):119-28. doi: 10.1016/j.jaad.2010.02.058.

24. Amini-Nik S, Kraemer D, Cowan ML, Gunaratne K, Nadesan P, Alman BA, et al. Ultrafast mid-IR laser scalpel: protein signals of the fundamental limits to minimally invasive surgery. PloS One. 2010;5(9):e13053. doi: 10.1371/ journal.pone.0013053.

25. Reilly MJ, Cohen M, Hokugo A, Keller GS. Molecular effects of fractional carbon dioxide laser resurfacing on photodamaged human skin. Arch Facial Plast Surg. 2010;12(5):321-5. doi: 10.1001/archfacial.2010.38.

26. Yurchenco PD, Schittny JC. Molecular architecture of basement membranes. FASEB J. 1990;4(6):1577-90. doi: 10.1096/fasebj.4.6.2180767.

27. Watt FM, Fujiwara H. Cell-extracellular matrix interactions in normal and diseased skin. Cold Spring Harb Perspect Biol. 2011;3(4):a005124. doi: 10.1101/cshperspect.a005124.

28. Mikesh LM, Aramadhaka LR, Moskaluk C, Zigrino P, Mauch C, Fox JW. Proteomic anatomy of human skin. J Proteomics. 2013;84:190-200. doi: 10.1016/j. jprot.2013.03.019.

29. Huang CM, Elmets CA, van Kampen KR, DeSilva TS, Barnes S, Kim H, et al. Prospective highlights of functional skin proteomics. Mass Spectrom Rev. 2005;24(5):647-60. doi: 10.1002/mas.20037.

30. Cole J, Tsou R, Wallace K, Gibran N, Isik F. Early gene expression profile of human skin to injury using highdensity cDNA microarrays. Wound Repair Regen. 2001;9(5):360-70. doi: 10.1046/j.1524-475x.2001.00360.x.

31. Gromov P, Skovgaard GL, Palsdottir H, Gromova I, Østergaard M, Celis JE. Protein profiling of the human epidermis from the elderly reveals up-regulation of a signature of interferon- $\gamma$-induced polypeptides that includes manganese-superoxide dismutase and the p85 $\beta$ subunit of phosphatidylinositol 3-kinase. Mol Cell Proteomics. 2003;2(2):70-84. doi: 10.1074/mcp.M200051MCP200.

32. O'Shaughnessy RF, Seery JP, Celis JE, Frischauf AM, Watt FM. PA-FABP, a novel marker of human epidermal transit amplifying cells revealed by $2 \mathrm{D}$ protein gel electrophoresis and cDNA array hybridisation. FEBS Lett. 2000;486(2):14954. doi: 10.1016/s0014-5793(00)02252-3.

33. Boxman IL, Hensbergen P, Van Der Schors R, Bruynzeel D, Tensen C, Ponec M. Proteomic analysis of skin irritation reveals the induction of HSP27 by sodium lauryl sulphate in human skin. Br J Dermatol. 2002;146(5):777-85. doi: 10.1046/j.1365-2133.2002.04714.x.

34. Huang CM, Foster KW, DeSilva T, Zhang J, Shi Z, Yusuf $\mathrm{N}$, et al. Comparative proteomic profiling of murine skin. J Invest Dermatol. 2003;121(1):51-64. doi: 10.1046/j.15231747.2003.12327.x

35. Rezaei-Tavirani M, Rezaei Tavirani M, Zamanian Azodi 
M, Razzaghi MR, Moravvej Farshi H. Evaluation of skin response after erbium: yttrium-aluminum-garnet laser irradiation: a network analysis approach. J Lasers Med Sci. 2019;10(3):194-99. doi:10.15171/jlms.2019.31.

36. Wenk J, Brenneisen P, Meewes C, Wlaschek M, Peters T, Blaudschun R, et al. UV-induced oxidative stress and photoaging. Curr Probl Dermatol. 2001;29:83-94. doi: 10.1159/000060656.

37. Takema Y, Yorimoto Y, Kawai M, Imokawa G. Age-related changes in the elastic properties and thickness of human facial skin. Br J Dermatol. 1994;131(5):641-8. doi: 10.1111/ j.1365-2133.1994.tb04975.x.

38. Schallreuter KU, Behrens-Williams S, Khaliq TP, Picksley SM, Peters EM, Marles LK, et al. Increased epidermal functioning wild-type p53 expression in vitiligo. Exp Dermatol. 2003;12(3):268-77. doi: 10.1034/j.16000625.2003.00084.x.

39. Bailet O, Fenouille N, Abbe P, Robert G, Rocchi S, Gonthier $\mathrm{N}$, et al. Spleen tyrosine kinase functions as a tumor suppressor in melanoma cells by inducing senescencelike growth arrest. Cancer Res. 2009;69(7):2748-56. doi: 10.1158/0008-5472.CAN-08-2690.

40. Pan TL, Wang PW, Lee WR, Fang CL, Chen CC, Huang $\mathrm{CM}$, et al. Systematic evaluations of skin damage irradiated by an erbium: YAG laser: histopathologic analysis, proteomic profiles, and cellular response. J Dermatol Sci. 2010;58(1):8-18. doi: 10.1016/j.jdermsci.2010.02.001.

41. Oender K, Trost A, Lanschuetzer C, Laimer M, Emberger $\mathrm{M}$, Breitenbach $\mathrm{M}$, et al. Cytokeratin-related loss of cellular integrity is not a major driving force of human intrinsic skin aging. Mech Ageing Dev. 2008;129(10):563-71. doi: 10.1016/j.mad.2008.05.008.

42. Porter RM, Leitgeb S, Melton DW, Swensson O, Eady R, Magin TM. Gene targeting at the mouse cytokeratin 10 locus: severe skin fragility and changes of cytokeratin expression in the epidermis. J Cell Biol. 1996;132(5):92536. doi: $10.1083 /$ jcb.132.5.925.

43. Wang JW, Peng SY, Li JT, Wang Y, Zhang ZP, Cheng Y, et al. Identification of metastasis-associated proteins involved in gallbladder carcinoma metastasis by proteomic analysis and functional exploration of chloride intracellular channel 1. Cancer Lett. 2009;281(1):71-81. doi: 10.1016/j. canlet.2009.02.020.

44. Duverger O, Morange M. Heat shock protein 25 plays multiple roles during mouse skin development. Cell Stress Chaperones. 2005;10(4):268-77. doi: 10.1379/csc-114r.1.
45. Chen B, Thomsen SL, Thomas RJ, Oliver J, Welch AJ. Histological and modeling study of skin thermal injury to $2.0 \mu \mathrm{m}$ laser irradiation. Lasers Surg Med. 2008;40(5):35870. doi: 10.1002/lsm.20630.

46. Fukuda Y, Ito Y, Azumi H, Eid N, Li Z, Marumo M, et al. Cell death and proliferation in Nd-YAG laser, electrocautery, and scalpel wounds on mice skin. J Dermatol Sci. 2002;28(2):106-18. doi: 10.1016/s0923-1811(01)00154-2.

47. El-Abaseri TB, Putta S, Hansen LA. Ultraviolet irradiation induces keratinocyte proliferation and epidermal hyperplasia through the activation of the epidermal growth factor receptor. Carcinogenesis. 2005;27(2):225-31. doi: 10.1093/carcin/bgi220.

48. Safari-Alighiarloo N, Taghizadeh M, Rezaei-Tavirani M, Goliaei B, Peyvandi AA. Protein-protein interaction networks (PPI) and complex diseases. Gastroenterol Hepatol Bed Bench. 2014;7(1):17-31. doi: 10.22037/ghfbb. v7i1.511.

49. Khayer N, Zamanian-Azodi M, Mansouri V, GhassemiBroumand M, Rezaei-Tavirani M, Heidari $\mathrm{MH}$, et al. Oral squamous cell cancer protein-protein interaction network interpretation in comparison to esophageal adenocarcinoma. Gastroenterol Hepatol Bed Bench. 2017;10(2):118-24. doi: 10.22037/ghfbb.v0i0.1119.

50. Abbaszadeh HA, Peyvandi AA, Sadeghi Y, Safaei A, Zamanian-Azodi M, Khoramgah MS, et al. Er: YAG laser and cyclosporin A effect on cell cycle regulation of human gingival fibroblast cells. J Lasers Med Sci. 2017;8(3):143-9. doi: 10.15171/jlms.2017.26.

51. Safaei A, Rezaei Tavirani M, Zamanian Azodi M, Lashay A, Mohammadi SF, Broumand MG, et al. Diabetic retinopathy and laser therapy in rats: A protein-protein interaction network analysis. J Lasers Med Sci. 2017;8(1):S20-S21. doi:10.15171/jlms.2017.s4.

52. Rostami-Nejad M, Rezaei-Tavirani M, Zadeh-Esmaeel MM, Rezaei-Tavirani S, Akbari Z, Esmaeili S, et al. Assessment of cytokine-mediated signaling pathway dysregulation in arm skin after $\mathrm{CO} 2$ laser therapy. J Lasers Med Sci. 2019;10(4):257-63. doi: 10.15171/jlms.2019.42.

53. Ogita M, Tsuchida S, Aoki A, Satoh M, Kado S, Sawabe M, et al. Increased cell proliferation and differential protein expression induced by low-level Er: YAG laser irradiation in human gingival fibroblasts: proteomic analysis. Lasers Med Sci. 2015;30(7):1855-66. doi: 10.1007/s10103-0141691-4. 